\title{
NEW RESEARCH LABORATORIES FOR THE CAMBRIDGE INSTRUMENT COMPANY, LTD.
}

\author{
By DR. M. C. MARSH \\ Head of Research Department
}

$\mathrm{O}^{\mathrm{N}}$ $\mathrm{N}$ October 14 a new block of research laboratories for the Cambridge Instrument Company, Ltd., was opened by Lord Adrian, Master of Trinity College and until recently Vice-Chancellor of the University of Cambridge. Following the opening, about 120 distinguished guests were entertained to lunch by the Directors of the Company, and they afterwards had an opportunity to inspect the new accommodation. On October 16 an open day was arranged for shareholders and for guests from the University and from several research establishments in the neighbourhood of Cambridge. About four hundred guests availed themselves of this opportunity. On both occasions the guests were received by Dr. P. Dunsheath, chairman of the Board of Directors, and Mr. H. C. Pritchard, managing director of the Company.

This new building is the result of a decision to expand greatly the research and development facilities of the Company. It provides about three times the previous floor area and permits the whole of these activities, which before this were dispersed in various parts of the works, to be brought under one roof, together with a design and drawing office.

The new laboratories are situated in Chesterton Road, adjacent to the Cambridge factory. They have a very fine view over the River Cam and over Jesus Green and provide accommodation suited to the work to be undertaken. As will be seen from Fig. 1, the clean, modern appearance of the building is emphasized by large windows that run the length of the first three floors and also by the colour contrast afforded by the light buff brickwork of the side walls and the dark green of the slate panels beneath the front windows. The building, which has a floor area of approximately 20,000 sq. $\mathrm{ft}$., has four storeys and is provided with a three-storied entrance block and a rear link block giving access to the factory buildings. The mode of construction gives a clear area on each floor entirely uninterrupted by columns or beams, and extensive use has been made of modern building materials and fittings, such as red thermoplastic flooring, heating coils embedded in the structure, double-glazed windows and acoustic panels.

The entrance block is distinguished by a spacious entrance hall, which is decorated in contemporary style and contains an instrument showroom and a reception area. The block also houses offices and $a$ lift serving all floors.

The laboratory block consists of four floors approximately $100 \mathrm{ft}$. long and $40 \mathrm{ft}$. wide. On the ground floor is the mechanical engineering laboratory with its offices, stores and constant-temperature room. Instrument makers' benches and experimental benches are arranged mainly beneath the front windows, and the remaining floor space is taken up by precision machine tools and mechanical laboratory equipment. The first floor is devoted to physies and electronics. It has a large and airy main laboratory, offices, dark room and optical laboratory, standards room and electronics workshop. The second floor houses the physical chemical laboratory which, in addition to offices, has special rooms for balances, glass-blowing and for chemical preparations. Polythene and 'Vulcathene' fittings are used in a special system for draining chemical waste from this floor. The top floor is taken up by design and drawing offices. Excellent lighting is provided by a number of rooflights in addition to windows running the entire length of both walls. Along the front of this floor is a covered balcony, edged with flower-boxes.

In designing the laboratories, great stress has been laid on versatility. With this in view all the services are laid in trunks of ample size, and it would be an easy matter to add any facilities not originally provided. Besides the usual supplies of gas, water and electricity, there is a special low-voltage electrical supply for portable apparatus. At 18 places there are boards containing four terminals and an appropriate switch. From a central control board it is possible to feed to these terminals a three-phase and neutral supply of any required voltage, single-phase a.c. of any voltage up to 250 volts at frequencies between 25 and 60 c./s., a.c. stabilized against changes of voltage and frequency and d.c. between 0 and 250 volts. These supplies are obtained from trans.

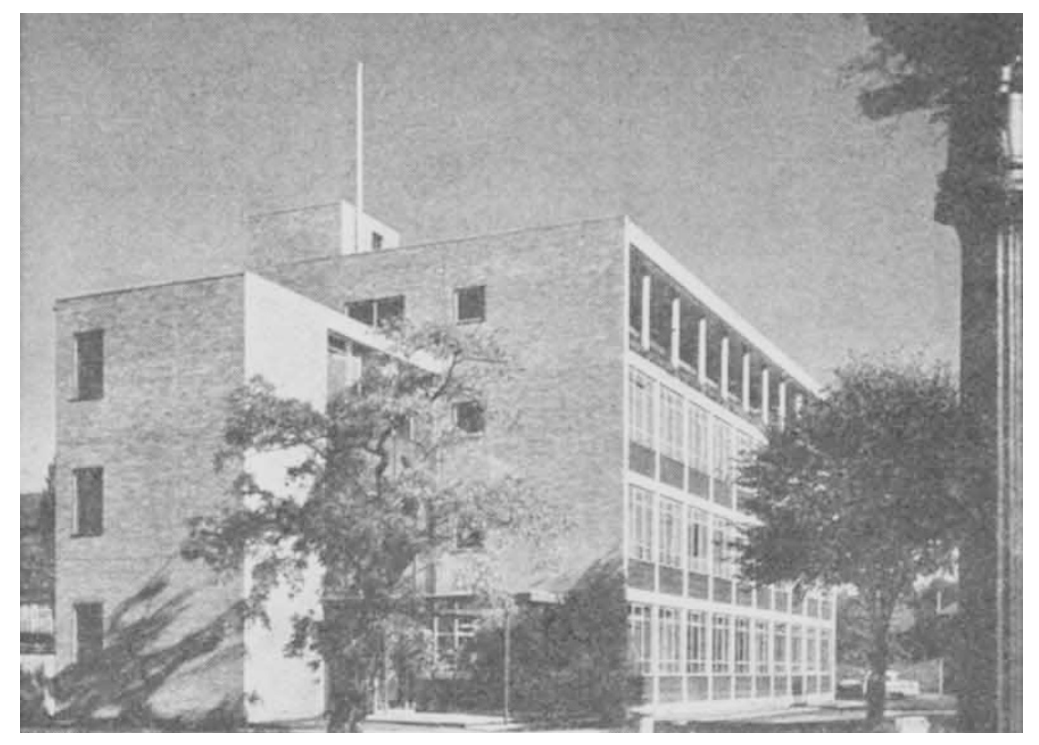

Fig. 1. Research Laboratories of the Cambridge Instrument Company, Ltd. 
formers, stabilizer and a Ward Leonard set with a connected motor alternator. The last two are situated in a cellar but are controlled from two points in the laboratories. On the third floor a large glass de-aerator of special design has been fitted in order to supply oxygen-free water for researches on boiler feedwater problems. Compressed air of high and low pressure is supplied to all laboratories, with an extra high-pressure supply in the mechanical laboratory.

The building was completed in the remarkably short time of just under one year by Messrs. J. Jarvis and Sons, Ltd. (London and Manchester), to the design of the architects, Messrs. Edward D. Mills and Partners. Light oak furniture with teak tops has been supplied to all the laboratories by Messrs. Baird and Tatlock (London), Ltd.

These laboratories are now fully occupied and, with an expanding staff, a large programme of research and development work is being undertaken. This programme relates to improvements to instruments which are already being manufactured, as well as to a number of entirely new projects in which the Company is interested.

\title{
CARBON-DATING CONFERENCE AT GRONINGEN
}

\author{
SEPTEMBER 14-19, 1959
}

$\mathrm{O}^{\mathrm{N}}$ $\mathrm{N}$ the invitation of Prof. Hl. de Vries (Natuurkundig Laboratorium) and Prof. H. T. Waterbolk (Archäologische-Biologisches Instituut), of the University of Groningen, a small conference of scientists from carbon-dating laboratories was held in Groningen during the week September 14-19. It was similar in character to the conferences held in Copenhagen, Cambridge and Andover, Mass., already reported in Nature $^{1,2}$ and Science ${ }^{3}$. Twenty-two dating laboratories were represented, some well established and others just getting into their stride, from twelve countries. We were happy for the first time to welcome Russian colleagues at these meetings. Some thirty-five communications were made to the meeting, which was partly concerned with the technique of carbon-dating and partly with selected aspects of its application to geological and archæological problems.

There was less emphasis than hitherto upon the techniques of counter and circuit design, but nonetheless there was a very interesting survey of the methods in use at various laboratories. Two laboratories described their scintillation counting techniques, that at Saclay, using paraldehyde, and that at Trinity College, Dublin, using methanol. While a few laboratories use acetylene or methane in their proportional gas-counters, it seems that the majority of dating laboratories now favour carbon dioxide counting. Considerable emphasis was laid on the need for careful pre-treatment of samples, especially with difficult materials such as bone, charcoal, caveearths and all samples of great age. Accounts were given of several promising investigations into matters affecting the principles of the method and its applications, as, for example, those at Heidelberg illustrating possible seasonal variations of radiocarbon content of the atmosphere. Particular interest was attracted by an account of the joint investigations of Cambridge, Copenhagen and Heidelberg upon possible fluctuations in the initial atmospheric carbon-I4 concentration during the past 1,200 years; this is a promising extension of ideas recently suggested by de Vries ${ }^{4}$ as possibly offering insight into past climatic changes.

Without attempting to summarize all the interesting contributions, it may suffice to point to two or three fields in which the application of carbon-dating has now apparently led to a highly significant advance in knowledge. First, we may note a series of datings made at Groningen of the earliest Neolithic cultures from south-eastern and central Europe, indicating a spread from the Near East across these regions as early as 4000 B.c.; these findings were paralleled to some extent by numerous datings made in Pisa upon Italian material.

Several contributions concerned the dating of stages of the last glaciation characterized by stratigraphy, archæology or biological and climatic evidence. Here the contribution of Groningen was particularly important, since the technique of isotopic enrichment had permitted the addition of several half-lives to the maximum possible age attainable ${ }^{5}$. With favourable materials that warrant this costly and lengthy process, ages as great as $64,000 \pm 1,100$ years are attainable. This in fact appears to be the date of the first mild interstadial period after the last (Eemian) interglacial. There is considerable evidence now for an interstadial about 30,000 years ago at several places in western Europe. From the American laboratories comes very convincing evidence obtained by dating ocean cores, and deposits both in the Caribbean and in salt lakes, for a very abrupt amelioration of climate about 11,000 years ago. It is striking that this climatic break corresponds exactly with the well-dated Late-Glacial period of climatic change in Europe.

A substantial part of the time of the meeting was properly devoted to various matters of co-ordination of the work of different laboratories. The successful outcome was reported of two policy decisions taken at earlier conferences, namely, to establish an agreed system of publication of date-lists and to publish a punch-card system of all published dates. The first of these objectives has been met by the publication of the Radiocarbon Supplement of the American Journal of Science, the first volume of which appeared in May of this year. The second was met by the formation of Radiocarbon Dates Association, Inc. Mr. Fred Johnson gave a description of the principles he had adopted in designing the punch-card system and reported the first issue of cards to subscribers. It is not yet sufficiently widely known by archæological, geological and biological laboratories concerned with the history of the past 70,000 years how massive is the contribution already made by carbon-dating to knowledge of this period, nor what a very rich source of information this punch-card system will provide. (Inquiries for subscriptions to the carbon-dating punch-card index should be directed to Radiocarbon Dates Association, Inc., Robert S. Peabody Founda- 